\title{
Eosinophils are an insignificant cellular component of rheumatoid synovium in patients with late stage disease: comparative distributions with mast cells and macrophages
}

\author{
Lynne C Tetlow, David E Woolley
}

\begin{abstract}
Objectives-To examine the distribution of eosinophils in rheumatoid synovial tissue and to determine whether or not their tissue distribution is related to that of mast cells or macrophages.

Methods-Consecutive tissue sections from 31 specimens of rheumatoid synovial tissue and cartilage-pannus junction were stained for eosinophils, mast cells, and macrophages with monoclonal antibodies and immunolocalisation techniques.

Results-Eosinophils were absent in 28 of the 31 specimens; the remaining three showed only the occasional eosinophil. By contrast the mean values for mast cell and macrophage (CD68/KP1 marker) distributions were 24 (SD 22) and 104 (SD 66) per $\mathbf{m m}^{2}$, respectively.

Conclusion-There are very few eosinophils in inflamed rheumatoid synovial tissue and sites of cartilage erosion despite the presence of appreciable numbers of macrophages and mast cells, the mast cells showing various states of activation. Such findings are at variance with those in allergic inflammation, in which the presence of eosinophils has been reported to be regulated by specific chemokines and adhesion molecules.
\end{abstract}

(Ann Rheum Dis 1996; 55: 548-551)

Eosinophilia has been described in several clinical and inflammatory syndromes, many of which have an allergic aetiology. ${ }^{12}$ However, eosinophilia has only rarely been noted in patients with rheumatoid arthritis as judged by cytological analyses of blood and synovial fluid, which consistently indicated less than $0.5 \%$ of patients with eosinophilia. ${ }^{3-5}$ Although seldom seen in rheumatoid synovial effusions, eosinophils have been reported to infiltrate the synovial tissue $^{35}$ where they may become activated by neutrophils to release the eosinophil cationic protein. ${ }^{6}$ Activated eosinophils release many other potent mediators such as basic and cationic proteins, neurotoxin, leukotrienes, cytokines, platelet aggregation factor, superoxide anions, and enzymes which potentially could damage both cells and extracellular matrix. ${ }^{2} 7$

The association and interactions of eosinophils, neutrophils, and mast cells in chronic inflammatory disorders has long been recognised and is well documented. ${ }^{28}$ Mast cells in particular are commonly found in tissues undergoing repair or matrix remodelling. ${ }^{8}$ From our recent reports of mast cell accumulations and evidence for mast cell activation in rheumatoid synovial tissue, especially at cartilage-pannus junctions, ${ }^{9}{ }^{10}$ it seemed likely that eosinophils would similarly represent a cellular component of the rheumatoid lesion. Mast cells are known to release various eosinophil activation factors such as histamine, granulocyte macrophage colony stimulating factor (GM-CSF), interleukin-3 (IL-3), and leukotriene $\mathbf{B}_{4}$ $\left(\mathrm{LTB}_{4}\right)$, as well as the eosinophilotactic factors prostaglandin $\mathrm{D}_{2}, \mathrm{LTB}_{4}$, IL-5, and GM-CSF. In this study sensitive immunolocalisation techniques employing monoclonal antibodies have been used to compare the distributions of eosinophils, mast cells, and macrophages in consecutive sections of rheumatoid synovial tissue and cartilage-pannus junctions.

\section{Materials and methods}

TISSUE SPECIMENS

Specimens of cartilage-pannus junction and rheumatoid synovial tissue were obtained from 31 patients with late stage classic rheumatoid arthritis undergoing arthroplasty of the knee. Seven patients were receiving low dose corticosteroid treatment before surgery. Joint tissues were transferred to the laboratory in Hanks' balanced salt solution and junctional specimens of cartilage/pannus were carefully sampled $(n=12)$. In addition, rheumatoid synovial tissues not immediately associated with cartilage or bone were obtained from remedial synovectomies $(n=19)$ and processed similarly. Usually three or four tissue samples were taken from different sites of the same specimen. All specimens were fixed for one hour in Carnoy's fixative and conventionally embedded in paraffin wax; $5 \mu \mathrm{m}$ sections were cut, dewaxed, rehydrated, and examined for the presence of eosinophils, mast cells, and macrophages.

IMMUNOLOCALISATION OF EOSINOPHILS, MAST CELL TRYPTASE, AND MACROPHAGES

Tissue sections were routinely stained with haematoxylin and eosin. In addition, mouse monoclonal antibodies to eosinophils (EG1 
and EG2, Pharmacia, St Albans, UK and Biogenesis, Poole, UK), mast cell tryptase (Chemicon International Inc, London, UK), and macrophages (CD68/KP1, Dako Ltd, High Wycombe, UK) were diluted in Trisbuffered saline (TBS) pH 7.6 to $1: 100,1: 300$, and 1:300, respectively, and applied to consecutive tissue sections for two hours at $20^{\circ} \mathrm{C}$. After three 10 minute washes in TBS, alkaline phosphatase conjugated goat antimouse IgG (Dako) diluted 1:50 in TBS was applied for one hour at $20^{\circ} \mathrm{C}$. After further washing the alkaline phosphate was developed using new fuchsin. The tissue sections were lightly counterstained with Harris's haematoxylin and mounted in Histomount permanent mountant.

For controls, the primary antibodies were substituted with TBS or normal mouse IgG (Dako) in concentrations of IgG similar to those of the primary antibodies; applications of these to consecutive tissue sections of each specimen consistently produced negative staining. Tissue sections of bowel specimens from patients with Crohn's disease were used in the immunostaining procedures to give a positive control for the eosinophil markers.

\section{PHOTOGRAPHY}

All micrographs were taken with a Zeiss photomicroscope III and Kodak T-Max Pro black and white film.

\section{CELL COUNTS}

Consecutive sections for 31 specimens immunostained for mast cells, macrophages, and eosinophils were examined for cell counts. For each specimen six fields per specimen using a $\times 16$ objective were counted for each of the three cell types. For cell counts of the
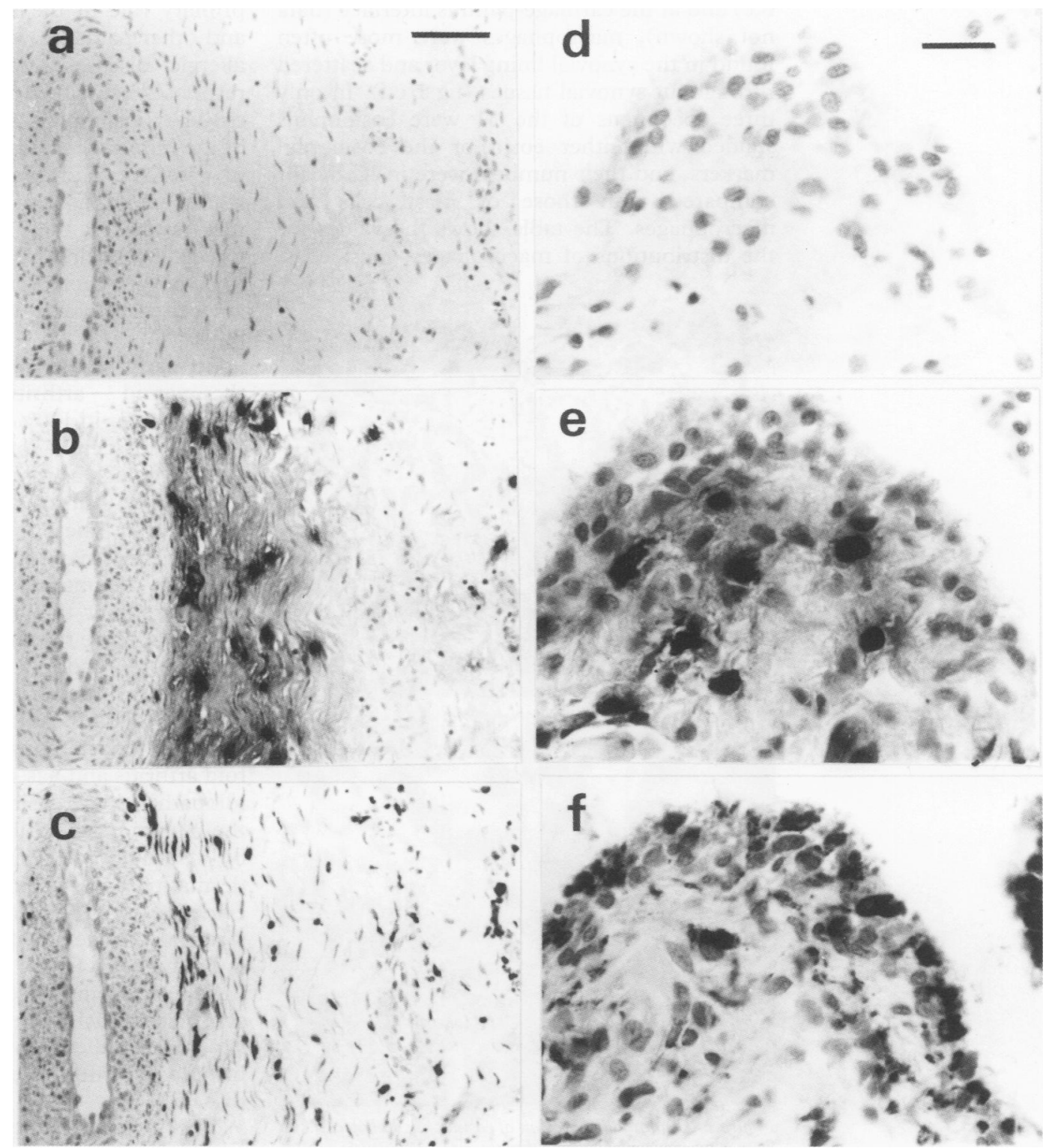

Figure 1 Immunohistochemical staining of rheumatoid synovium to show eosinophils, mast cells, and macrophages. (a), (b), and (c) Consecutive sections of synovium at low power. No eosinophils were seen (a); mast cells both intact and activated (as judged by extracellular tryptase shown by dark staining of extracellular matrix are shown confined to the central panel of the micrograph (b); macrophages (darkly stained) are also seen throughout the tissue, (c). Bar $=100 \mu m$. $(d)$, (e), and ( $f$ ) Consecutive sections of rheumatoid synovium at high power. (d) Eosinophils were absent, (e) mast cells with extracellular tryptase were observed throughout the tissue, and $(f)$ macrophages were seen mainly confined to the synovial lining layer. Bar $=30 \mu \mathrm{m}$. All sections were counterstained with haematoxylin. 
cartilage-pannus specimens the area occupied by cartilage was limited to no more than $10 \%$ of the microscopic field. One $\times 16$ field on the Zeiss microscope approximated to $1 \mathrm{~mm}^{2}$.

\section{Results}

Eosinophils were absent in 16 of 19 rheumatoid synovial specimens and in all 12 specimens of cartilage-pannus junction examined. Consecutive sections of these specimens showed variable tissue distributions for mast cells and macrophages (fig 1). In 26 of the 31 specimens examined numerous mast cells and macrophages were present, whereas in other specimens either mast cells or macrophages predominated in a specific location. There seemed to be no correlation between the distributions of mast cells and macrophages. Whereas mast cells were randomly distributed, either singly or in clusters, throughout the synovial tissue (fig 1 $b, e)$ and at the cartilage-pannus interface (data not shown), macrophages were more often found in the synovial lining layer and scattered throughout synovial tissues (fig $1 \mathrm{c}, \mathrm{f}$ ). In only three specimens of the 31 were eosinophils stained with either eosin or the eosinophil markers, and their numbers were insignificant compared with those of mast cells and macrophages. The table shows the values for the distributions of macrophages, mast cells,

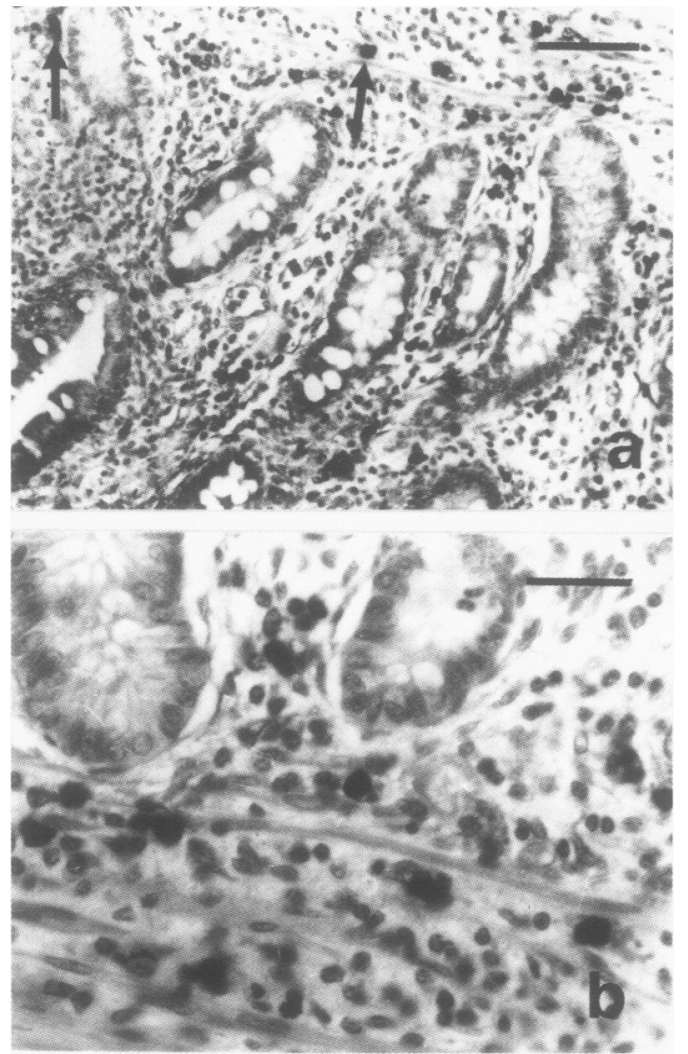

Figure 2 Immunolocalisation of eosinophils in bowel tissue from a patient with Crohn's disease, used as positive control for the eosinophil markers. (a) Low power photomicrograph showing distribution of eosinophils (darkly stained, examples arrowed) in Crohn's disease tissue stained with EG1 marker. Bar = $100 \mu \mathrm{m}$. (b) High power photomicrograph of positive control for the eosinophil marker EG2. Bar =

$30 \mu \mathrm{m}$ and eosinophils for the 31 rheumatoid tissue specimens.

Confirmation that the three different eosinophil markers were functional and effective was provided by the staining of numerous eosinophils in tissue sections of bowel specimens from patients with Crohn's disease, prepared in the same way as the rheumatoid tissues (fig 2).

\section{Discussion}

Rheumatoid arthritis is a disease characterised by chronic inflammation, cartilage destruction, and severe joint deformity. The importance of the synovial pannus in cartilage erosion has long been recognised and early histological studies of synovium and cartilage-pannus junctions from rheumatoid tissues have shown various cell types including fibroblasts, macrophages, neutrophils, $T$ lymphocytes, and mast cells. ${ }^{1112}$ Eosinophils, although having a primary role in the elimination of helminths and other parasites, increase their numbers in allergic diseases and various inflammatory responses associated with lung, skin, and gut tissues. ${ }^{2}$ Eosinophils can participate in all steps of the immune response; they provide a source of cytotoxic and proinflammatory mediators which are capable of exacerbating inflammatory processes; they may damage connective tissues by their collagenolytic enzymes and toxic oxygen metabolites; and have often been associated with activated mast cells or neutrophils. ${ }^{12}$

An early study on 45 patients with severe rheumatoid arthritis reported vascular eosinophilia in $40 \%$; these patients had a higher incidence of extra-articular manifestations such as vasculitis, pleuropericarditis, pulmonary fibrosis, and subcutaneous nodules. ${ }^{13}$ These findings suggest that eosinophilia may be one marker of extraarticular rheumatoid disease associated with vascular rather than primary joint pathology. However, more recent studies over the past 20 years have reported that less than $0.5 \%$ of patients with rheumatoid arthritis have eosinophilia. ${ }^{3-5}$ Tissue eosinophilia has only occasionally been reported in selected cases of rheumatoid arthritis and has usually been linked to the idiopathic hypereosinophilia syndrome $\mathrm{e}^{35}$ or the benign eosinophilic disorder characterised by nodules, eosinophilia, rheumatism, dermatitis, and swelling. ${ }^{14}$ As some histological evidence for eosinophils in rheumatoid synovial tissue had been published for individual cases, ${ }^{35}$ the raised eosinophilic cationic protein concentrations in rheumatoid synovial fluids reported by Hallgren et $a l^{6}$ supported the contention that these cells may have a harmful role in inflammatory joint disease.

The present study has been unable to support that view, despite evidence of numerous mast cells in most specimens, many showing evidence of mast cell activation with the associated release of histamine and eosinophil chemoattractants. Mast cell histamine also enhances the recruitment of 
Distribution of macrophages, mast cells, and eosinophils in rheumatoid tissues ( $n=31)$

\begin{tabular}{llc}
\hline Cell type & Antibody & Cells $\times 16$ field \\
& & mean $(S D)$ \\
\hline Macrophage & CD68/KP1 & $104 \cdot 8(66 \cdot 1)$ \\
Mast cell & MC tryptase & $24 \cdot 1(22 \cdot 3)$ \\
Eosinophil & EG1 and EG2 & $0 \cdot 22(0 \cdot 57)$ \\
\hline
\end{tabular}

$\star \times 16$ field as described in Methods.

eosinophils into inflammatory lesions, a chemotactic process mediated by both histamine ${ }_{1}\left(\mathrm{H}_{1}\right)$ and $\mathrm{H}_{2}$ receptor stimulation, as well as by $\mathrm{H}_{1}$ mediated enhancement of complement directed chemotaxis. ${ }^{15}$ The monocyte-macrophage distribution was usually much greater than that for mast cells (table) and macrophagic products such as GM-CSF, platelet aggregation factor, and tumour necrosis factor- $\alpha$ are recognised activators and attractants for eosinophils. ${ }^{2}$ It was therefore surprising to note the virtual absence of eosinophils, conclusions based on careful histological and quantitative analyses of 31 synovial specimens, most of which contained numerous inflammatory cells rather than representing quiescent, fibrotic synovial pannus specimens, as previously described. ${ }^{911}$ In addition, although polymorphonuclear leucocytes have often been reported to be important cellular components of rheumatoid synovial tissue, ${ }^{12}$ it was also noted that these cells were only rarely seen in the specimens examined.

Why eosinophils are virtually absent from inflamed rheumatoid synovial tissues, but not, for example, from inflammatory conditions of the skin, lung, or gut remains uncertain. One explanation may relate to the selective production of specific chemokines, inducible proteins related to interleukin-8, by different types of inflammation in various tissues. For example, in allergic inflammation chemokines such as monocyte chemotactic protein-1 (MCP-1), MCP-3, RANTES, and macrophage inhibitory protein (MIP-1 $\alpha)$ induce the recruitment and activation of eosinophils and basophils via GTP binding protein-coupled receptors. ${ }^{16}$ Because RANTES and MCP-3 are recognised as the major chemokines for eosinophils $^{16}$ it seems possible that their production by rheumatoid synovial tissue may not be as prominent as that by allergic inflammatory tissues. Similarly, migration of eosinophils and their residence in tissues also relates to the availability of specific adhesion molecules such as the integrins, selectins, and the immunoglobulin superfamily, which allow cell:cell and cell:matrix interactions. ${ }^{217}$ Although we cannot exclude the possibility that eosinophils may show a transient and rapid infiltration of rheumatoid synovial tissue at earlier stages of disease activity, we conclude that eosinophils in general represent an insignificant cellular component of all our synovial tissue specimens examined to date.

This work was supported by research grant WO147 from the Arthritis and Rheumatism Council, UK. We thank consultant orthopaedic surgeons T Dunningham (Tameside Hospital, Manchester), M Morris (Devonshire Royal Hospital, Buxton), and $\mathrm{H}$ Bertfield (Wythenshawe Hospital, Manchester) for the supply of rheumatoid tissues; and Dr M Bromley and Claire NcNulty for preliminary studies.

1 Weller P F. Eosinophil structure and function. In: D J McCarty, W J Koopman, eds. Arthritis and allied conditions, 12th ed. London: Lea Febiger, 1993: 409-16.

2 Adolphson C R, Gleich G J. Eosinophils. In: Holgate S T, Church M K, eds. Allergy. London: Gower Medical, 1993: 6.1-6.12.

3 Panush R S, Alejandro E, Franco M D, Schur P H. Rheumatoid arthritis associated with eosinophilia. Ann Rheumatoid arthritis associated

4 Brown J P, Rola-Pleszczynski M, Menard H-A. Eosinophilic synovitis: clinical observations on a newly recognised subset of patients with dermatographism. Arthritis Rheum 1986; 29: 1147-51.

5 Martin-Santos J M, Mulero J, Andreu J L, de Villa L F, Bernaldo-de Quiros L, Noguera E. Arthritis in idiopathic hypereosinophilic syndrome. Arthritis Rheum 1988; 31: $120-5$.

6 Hallgren R, Bjelle A, Venge P. Eosinophilic cationic protein in inflammatory synovial effusions as evidence of eosinophilic involvement. Ann Rheum Dis 1984; 43: 556-62.

7 Davis W B, Fells G A, Sun X-H, Gadek J E, Venet A, Crystal R G. Eosinophil-mediated injury to lung parenchymal cells and interstitial matrix. $\mathfrak{f}$ Clin Invest parenchymal cells

8 Church M K, Caulfield J P. Mast cell and basophil functions. In: Holgate $S \mathrm{~T}$, Church $\mathrm{M} \mathrm{K}$, eds. Allergy. London: Gower Medical, 1993: 5.1-5.12.

9 Tetlow L C, Woolley D E. Distribution, activation and tryptase/chymase phenotype of mast cells in the rheumatoid lesion. Ann Rheum Dis 1995; 54: 549-55.

10 Tetlow L C, Woolley D E. Mast cells, cytokines and metalloproteinases at the rheumatoid lesion: dual immunolocalisation studies. Ann Rheum Dis 1995; 54: 896-903.

11 Bromley M, Woolley D E. Histopathology of the rheumatoid lesion. Identification of cell types at sites of cartilage erosion. Arthritis Rheum 1984; 27: 857-63.

12 Woolley D E. Cellular mechanisms of cartilage destruction. In: Henderson B, Edwards J, Pettifer R, eds. Mechanisms In: Henderson B, Edwards J, Pettifer R, eds. Mechanisms Press, 1995: 115-32.

13 Winchester R J, Litwin S D, Koffler D, Kunkel H G. Observations on the eosinophilia of certain patients with rheumatoid arthritis. Arthritis Rheum 1971; 14: 650-65.

14 Butterfield J H, Leiferman K M, Gleich G J. Nodules, eosinophilia, rheumatism, dermatitis and swelling (NERDS): a novel eosinophilic disorder. Clin Exp Allergy 1993; 23: 571-80.

15 White M V, Kaliner M A. Histamine. In: Gallin J R, Goldstein I M, Snyderman R, eds. Inflammation: basic principles and clinical correlates. New York: Raven Press, 1988: 169-93.

16 Baggiolini M, Dahinden C A. CC chemokines in allergic inflammation. Immunol Today 1994; 15: 127-33.

17 Spry C J F, Kay A B, Gleich G J. Eosinophils. Immunol Today 1992; 13: 384-7. 